\title{
Uso de lógica booleana na triagem de áreas aptas para a implantação de aterro sanitário no Município de Campina Verde, Minas Gerais, Brasil
}

\section{Renata Costa Lopes ${ }^{1}$ e Raquel Naiara Fernandes Silva ${ }^{2}$}

\author{
${ }^{1}$ Universidade Federal de Uberlândia. Curso de Engenharia Ambiental e Sanitária. \\ Av. João Naves de Ávila, 2121. Santa Mônica. Uberlândia-MG, Brasil \\ (CEP 38400-902). E-mail: renata.costa11@gmail.com. \\ ${ }^{2}$ Universidade Federal de Uberlândia. Faculdade de Engenharia Civil. Av. João \\ Naves de Ávila, 2121. Santa Mônica. Uberlândia-MG, Brasil (CEP 38400-902).
}

Resumo. A redução das milhões de toneladas de lixo que a civilização produz todos os dias é um dos maiores desafios da atualidade. No Brasil, dar destinação correta a esse lixo é uma meta ainda distante. Em Minas Gerais, cerca de 25,29\% da população urbana reside em áreas que não possuem meios de descarte de seus resíduos sólidos em aterros sanitários, destinando-os em lixões e/ou aterros controlados. Neste contexto, este estudo tem como objetivo avaliar a aptidão de áreas para a instalação de aterros sanitários no Município de Campina Verde-MG, com o uso de SIG e apoio à decisão através da lógica booleana. Uma análise criteriosa destes espaços territoriais é importante para garantir a minimização dos impactos ambientais provenientes desse tipo de empreendimento. A metodologia deste estudo consistiu no estabelecimento dos critérios de restrição, originando mapas booleanos com classificação de apto/não apto. 0 resultado foi o mapa de aptidão para a instalação de aterro sanitário, que revelou $1.924,64 \mathrm{~km}^{2}$ de área apta à instalação de aterro sanitário. A conclusão do estudo caracteriza as técnicas de geoprocessamento como uma ferramenta eficaz, rápida e de baixo custo, que podem vir a ser aplicadas em outros municípios, facilitando desta maneira a disposição final adequada dos resíduos sólidos urbanos.

Palavras-chave: Aterro sanitário; Lógica booleana; Resíduos sólidos urbanos; Sistema de Informação Geográfica.

Abstract. Use of boolean logic in the screening of suitable areas for the implementation of a landfill in the Municipality of Campina Verde, Minas Gerais State, Brazil. The reduction of the millions of tons of garbage that our civilization produces every day is one of the biggest challenges of today. In Brazil to give this garbage a correct destination is a distant goal. Approximately $25.29 \%$ of the urban population of Minas Gerais State, Southeast Brazil, occupy areas that have no means of disposal in landfills, thus disposing their solid waste in dumps
Recebido $06 / 04 / 2020$

Aceito

$13 / 06 / 2020$

Disponível on line $15 / 06 / 2020$

Publicado $31 / 08 / 2020$

Acesso aberto

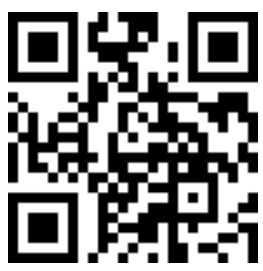

ORCID

(D) 0000-0002-6233-2794 Renata Costa Lopes

(D) 0000-0002-8010-8251

Raquel Naiara

Fernandes Silva

ISSN 2359-1412/RBGAS-2020-0056/2020/7/16/3/487

Rev. Bras. Gest. Amb. Sustent.

http://revista.ecogestaobrasil.net 
and/or controlled landfills. In this context, this study aims to assess the suitability of areas for the installation of landfills in the Municipality of Campina Verde, Minas Gerais State, Brazil, using GIS, with support for decision-making through Boolean logic. A careful analysis of these territorial spaces is important to ensure the minimization of environmental impacts from this type of enterprise. The methodology of this study consisted in the establishment of the restriction criteria, originating Boolean maps with classification of fit/not fit. The result was the aptitude map for the landfill installation, which revealed $1,924.64 \mathrm{~km}^{2}$ of area suitable for the landfill installation. The conclusion of the study characterizes the geoprocessing techniques as an effective, fast and low cost tool, which can be applied in other municipalities, thus facilitating the proper final disposal of solid urban waste.

Keywords: Landfill; Boolean logic; Urban solid waste; Geographic Information System.

\section{Introdução}

A quantidade de resíduos sólidos em um país está diretamente relacionada à evolução da sua população, ao nível de urbanização, ao desenvolvimento econômico e social, e ao poder de compra dos seus habitantes.

Besen (2007) alerta para o fato de que a redução das milhões de toneladas de lixo que nossa civilização produz todos os dias é um dos maiores desafios da atualidade e que no Brasil, dar uma destinação correta a esse lixo é uma meta ainda distante.

O Brasil apresenta uma área de $8.515 .767,049 \mathrm{~km}^{2}$ e é o $5^{0}$ país em extensão territorial do mundo, com uma estimativa de população de 210,1 milhões de habitantes e uma taxa de crescimento populacional de $0,79 \%$ ao ano (IBGE, 2019). Para Jucá (2002), existe uma relação entre o Produto Interno Bruto (PIB) e a geração per capita de resíduos sólidos. Segundo o Banco Nacional do Desenvolvimento (BNDES, 2014) a região sudeste concentra mais de $50 \%$ do PIB e é responsável pela geração de aproximadamente $50 \%$ dos resíduos sólidos no país.

Considerando dados do IBGE (2017), cerca de 25,29\% da população urbana de Minas Gerais residem em áreas que não possuem meios de descarte em aterros sanitários, destinando assim seus resíduos sólidos em lixões e/ou aterros controlados.

Sendo assim, é importante destacar que a geração de resíduos e, consequentemente, seu tratamento e disposição final estão relacionados não apenas à população ou PIB de uma região, estado ou município, mas também à gestão e ao gerenciamento dos resíduos pelo poder municipal, que é capaz de implementar ações que incentivem a redução ou o aproveitamento desses resíduos (ABRELPE, 2012).

No Brasil predomina o uso de uma única técnica de tratamento e disposição final, o aterro sanitário. Segundo Hamada (2003), os aterros sanitários compreendem uma forma segura de disposição dos resíduos, pela especificação em locais apropriados como pela implementação de sistemas de impermeabilização, drenagem, cobertura diária e final e tratamento dos efluentes líquidos e gasosos gerados.

De acordo com a ABNT NBR 8419:1992 (ABNT, 1992), aterros sanitários de resíduos sólidos urbanos

consistem na técnica de disposição de resíduos sólidos urbanos no solo, sem causar danos ou riscos à saúde pública e à segurança, minimizando os impactos 
ambientais, método este que utiliza os princípios de engenharia para confinar os resíduos sólidos ao menor volume permissível, cobrindo-os com uma camada de terra na conclusão de cada jornada de trabalho ou a intervalos menores se for necessário (ABNT, 1992).

Para a instalação de aterros sanitários, são necessários que sejam realizadas a impermeabilização total do local que receberá os resíduos sólidos, bem como a instalação de redes para coleta e tratamento do chorume, material que reúne todas as impurezas líquidas e tóxicas do lixo. Ressalta-se que os gases que fluem do aterro sanitário são captados e tratados e a qualidade e a quantidade dos resíduos sólidos depositados também são monitoradas (Portela e Ribeiro, 2014). Contudo, a disponibilidade de áreas para a disposição de resíduos sólidos apresenta-se cada vez mais escassa, devido à crescente urbanização.

Além disso, verifica-se que a administração municipal incumbida do gerenciamento dos resíduos sólidos urbanos comumente opta por áreas que possuem menor valor econômico e nem sempre adequados sob o ponto de vista ambiental.

Assim, a complexidade inerente deste tipo de análise vem sendo reduzida com o auxílio de técnicas de geoprocessamento. Para tanto, ferramentas computacionais, como softwares de Sistemas de Informação Geográfica (SIG), fornecem suporte para discriminar áreas potenciais para instalação de aterros sanitários, de maneira mais rápida e eficiente (Samizava et al., 2008).

Segundo Amaral (2017) o uso da análise multicritério juntamente com a álgebra booleana mostrou-se satisfatória permitindo a obtenção de investigação rápida e clara. Para Figueredo Neto et al. (2010), o uso da análise multicritério combinada com a álgebra booleana mostra-se ser uma importante ferramenta de geoprocessamento auxiliando análises de cunho ambiental.

Segundo dados da Fundação Estadual do Meio Ambiente de Minas Gerais (FEAM, 2019), o Município de Campina Verde está inserido no Território de Desenvolvimento Triângulo Norte que é formado por 30 municípios e possui uma população urbana de 1.228.395 habitantes (IBGE, 2017). Nos quais a disposição irregular é utilizada por 20,4\% da população urbana deste território, sendo que $17,5 \%$ dispõe seus resíduos em lixões (18 municípios) e 2,9\% em aterro controlado (dois municípios).

Neste contexto, o presente trabalho tem como objetivo indicar áreas aptas à instalação de um aterro no Município de Campina Verde (MG) com o emprego de geotecnologias, tomando-se como base a lógica booleana como apoio à decisão.

\section{Materiais e métodos}

\section{Área de estudo}

O Município de Campina Verde está situado na Mesorregião do Triângulo Mineiro/Alto Paranaíba, localizado nas coordenadas geográficas de referência 19³2'09" de latitude sul e $49^{\circ} 29^{\prime} 09^{\prime \prime}$ de longitude oeste, estando a uma altitude de $532 \mathrm{~m}$. A área da unidade territorial do município é de $3.650,749 \mathrm{~km}^{2}$, com uma população estimada pelo IBGE de 19.745 pessoas no ano de 2019. A Figura 1 demonstra a posição geográfica do município em relação ao estado de Minas Gerais. 


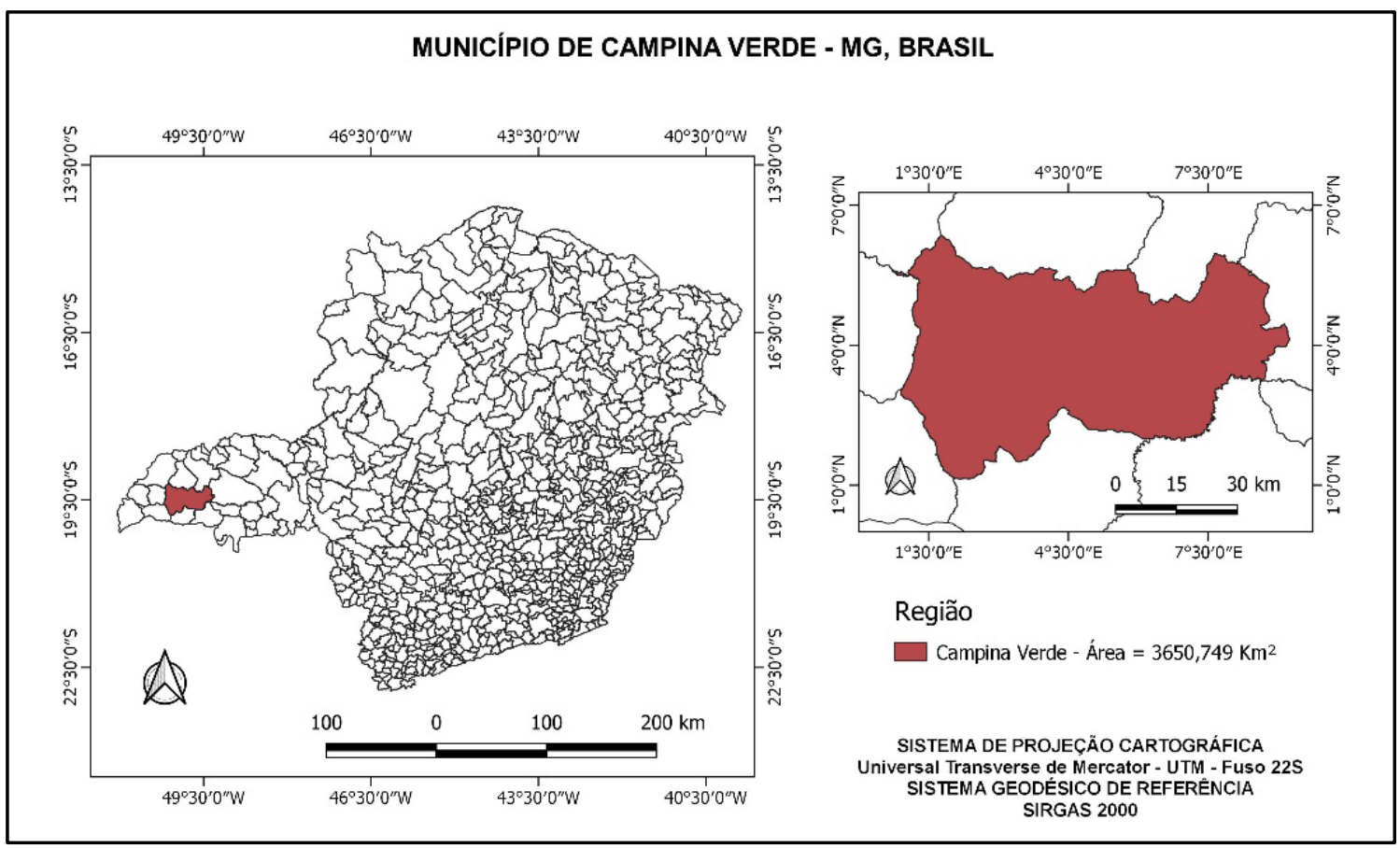

Figura 1. Localização do município de Campina Verde (MG).

O clima na Região de Campina Verde é caracterizado por apresentar totais pluviométricos médios anuais entre 1.200 a $1.500 \mathrm{~mm}$, de clima tropical quente e úmido. 0 período seco é de abril a setembro e a estação seca coincide com o mês mais frio (Franco e Rosa, 1998).

Nas áreas não antropizadas, o bioma predominante é o cerrado, caracterizado por vegetação de gramíneas e arbustos de troncos retorcidos, além de árvores de maior porte em regiões de drenagem perene.

\section{Procedimentos metodológicos}

Dentre as diversas ferramentas que auxiliam na tomada de decisão, nesse trabalho fez-se uso da lógica booleana por ser uma lógica de implementação relativamente simples juntamente com o Sistema de Informação Geográfica (SIG) e fazendo uso do software livre Quantum Gis (QGis) que se trata de uma multiplataforma de SIG.

Os critérios utilizados para determinar as alternativas locacionais do aterro sanitário, se basearam em aspectos normativos.

\section{Geração dos mapas}

Mapas de declividade apresentam vital importância para a análise de relevo, sendo uma forma de representação temática da distribuição espacial dos diferentes níveis de inclinação existentes em um terreno amparando a análise da paisagem (Colavite e Passos, 2012).

O mapa de declividade do Município de Campina Verde foi obtido através de um modelo digital de elevação (MDE) oferecido pelo projeto Topodata do Instituto Nacional de Pesquisas Espaciais (INPE) e classificado segundo a Empresa Brasileira de Pesquisa Agropecuária (EMBRAPA).

Os mapas pedológicos apresentam a distribuição espacial dos solos, tendo assim informações dos recursos naturais de uma dada área. Neste aspecto, a pedologia tem um papel fundamental no entendimento dos fatores de formação do solo e da sua fragilidade. 
O mapa de solos do Município de Campina Verde foi obtido e classificado por meio de dados fornecidos pela Empresa Brasileira de Pesquisa Agropecuária (EMBRAPA).

O mapa de estradas e de hidrografia de Campina Verde foi obtido a partir do Catálogo de Dados Espaciais do IEDE (Infraestrutura Estadual de Dados Espaciais de Minas Gerais). Já o mapa de área urbana foi efetivado através de bases de dados fornecidas pela plataforma de Infraestrutura de Dados Espaciais da IEDE.

Após a estruturação e padronização dos mapas temáticos dos fatores utilizados para definição das áreas aptas para instalação de aterro sanitário, desenvolveu-se uma regra de decisão para alcançar os objetivos do estudo. Portanto, o geoprocessamento se caracteriza como um instrumento de redução da subjetividade no processo de decisão, no qual foi possível atribuir pesos aos fatores considerados nesta análise.

\section{Lógica booleana}

A lógica booleana surgiu durante o século XIX, que foi justamente uma das épocas de maior desenvolvimento da história da matemática desde os tempos da Idade da Grécia (Boyler, 1968). A definição desta lógica passa por diversos conceitos e leis definidas para expressar em termos algébricos uma forma de raciocínio humano.

Pela perspectiva booleana, um elemento está dentro ou fora de um dado conjunto. Os conjuntos são considerados como sistemas bivalentes com seus próprios estados alternando entre inclusão ou exclusão. Assim, um elemento tem grau de pertinência 0 se não pertencer ao conjunto e grau de pertinência 1 se o elemento pertencer ao conjunto.

Segundo Câmara et al. (2007) a álgebra booleana é uma estrutura algébrica que captura as propriedades essenciais dos operadores lógicos e de conjuntos, ou ainda oferece uma estrutura para se lidar com afirmações. A partir do Diagrama de Venn é possível observar a aplicação de operadores utilizados nesse tipo de algoritmo. Ele utiliza ferramentas lógicas AND (interseção), OR (união), NOT (negação) e XOR (exclusão) como representado na Figura 2.

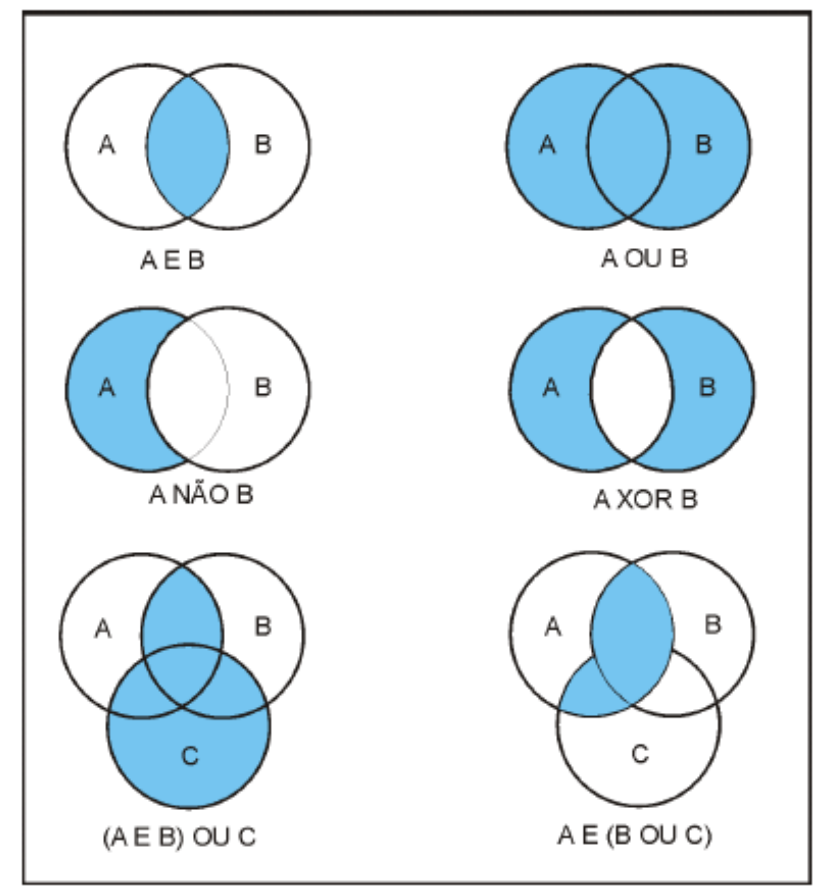

Figura 2. Diagrama de Venn. Fonte: Câmara et al. (2007). 
Sendo assim, os planos de informação classificados como restrições possuem caráter booleano e eliminam as áreas que, devido às impossibilidades técnicas ou legais, não podem ser utilizadas para destinação de resíduos sólidos.

A fim de aplicar essa lógica realizou-se a classificação dos critérios com valores binários (0 ou 1) que serão apresentados como um dos resultados desta pesquisa.

\section{Resultados}

A Figura 3 apresenta os mapas de declividade e pedologia do Município de Campina Verde. A extensão territorial do município apresenta um relevo plano e solos de estrutura bem desenvolvida como é o caso dos Latossolos.

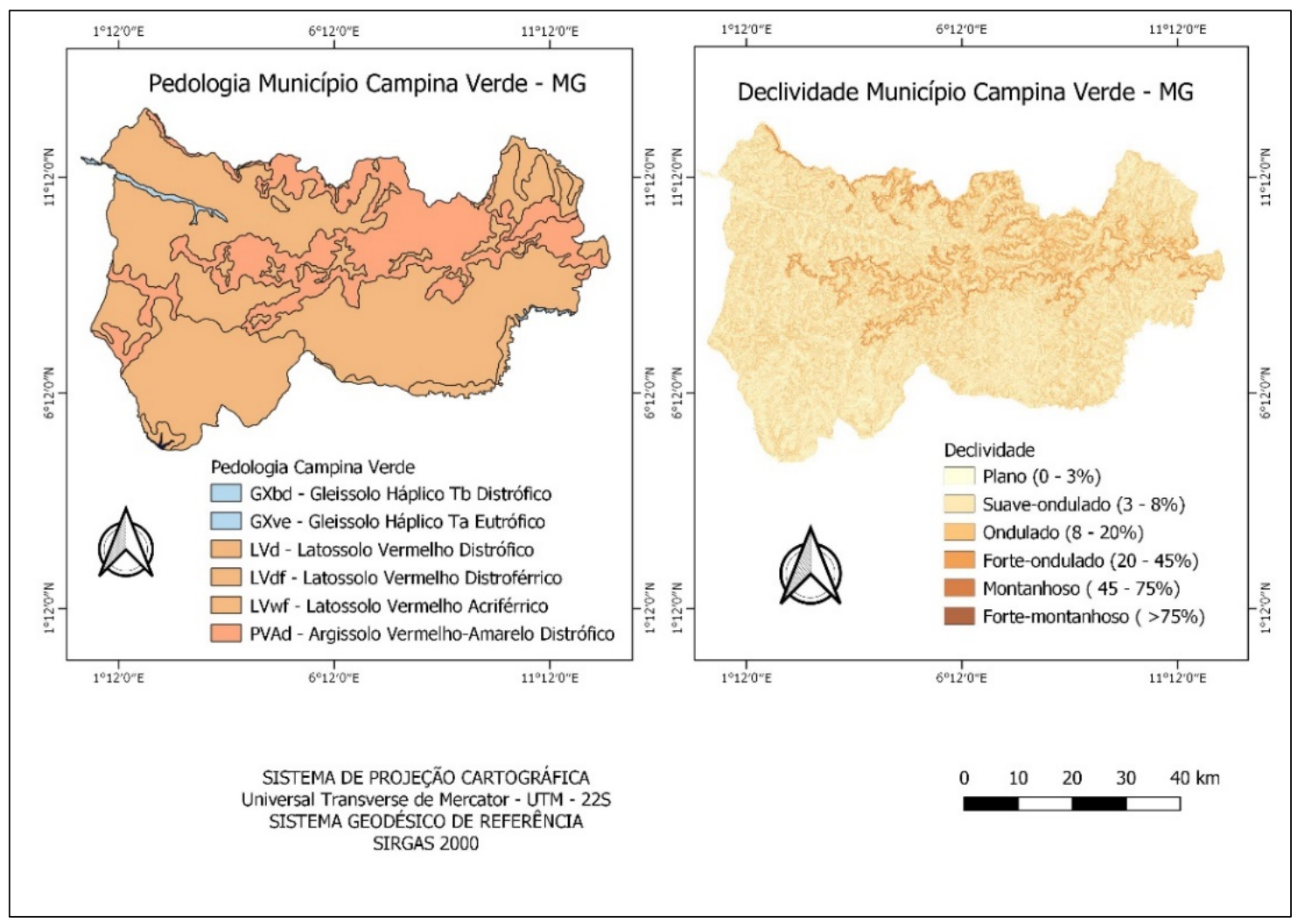

Figura 3. Declividade e pedologia do Município de Campina Verde (MG).

Para os mapas de estrada, hidrografia e área urbana foi realizado o procedimento de cálculo de distância, gerando assim mapas de distâncias (buffer), de acordo com os critérios estabelecidos pela ABNT NBR 13896:1997 (ABNT, 1997) e por Silva (2009) (Figura 4). 


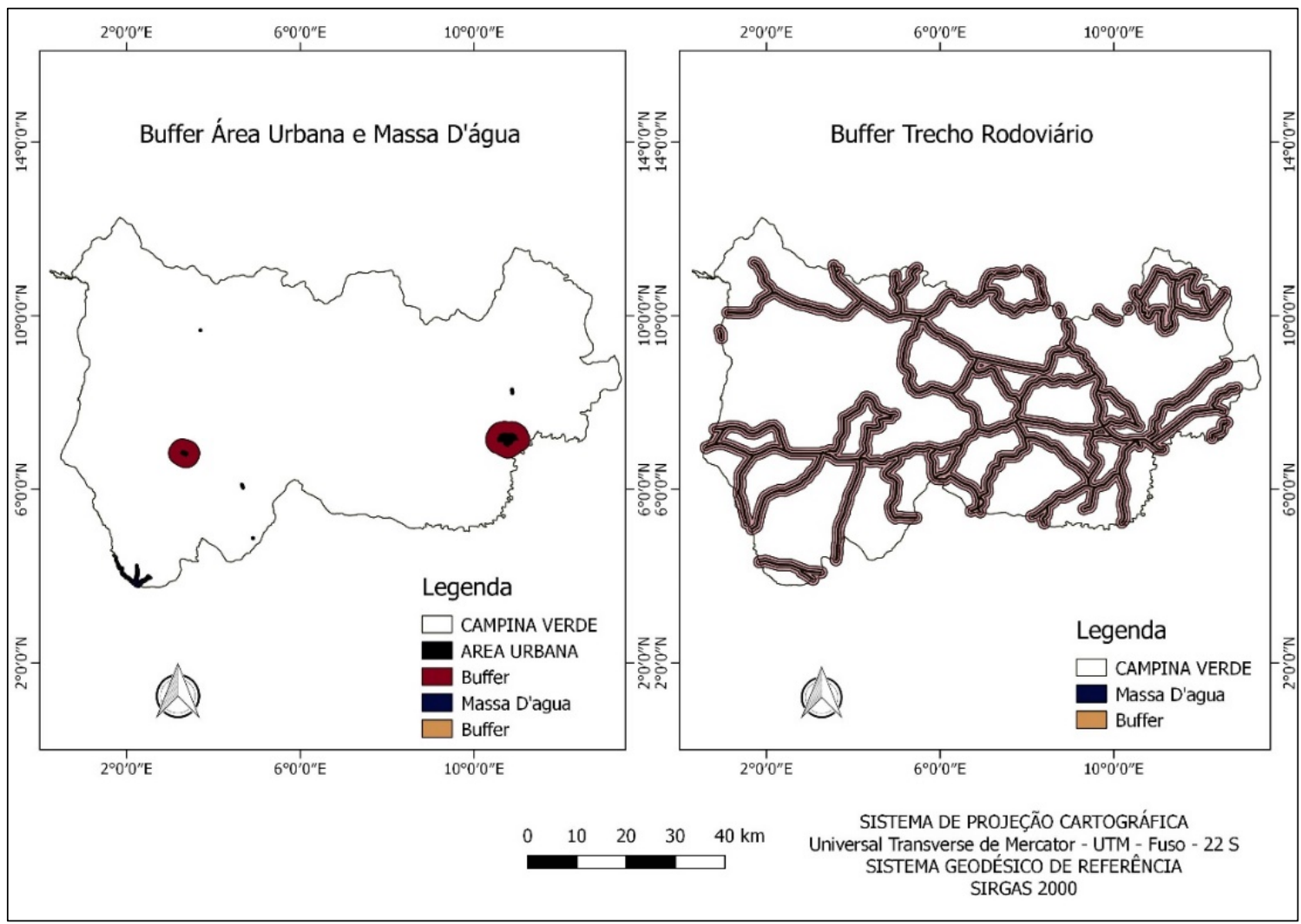

Figura 4. Mapas de distâncias.

A atribuição de valores binários, sendo 0 para critérios com baixa pertinência ou restrito e 1 para critérios pertinentes foi realizada de forma subjetiva, embasada em diversos autores e nas normativas sobre o tema, chegando à seguinte formatação (Tabela 1).

Tabela 1. Critérios e valores de análise.

\begin{tabular}{|l|c|c|}
\hline Mapas & Classes & Notas \\
\hline \multirow{3}{*}{ Pedologia } & Latossolo & 1 \\
\hline \multirow{4}{*}{ Declividade } & Argissolo & 0 \\
\cline { 2 - 3 } & Gleissolo & 0 \\
\cline { 2 - 3 } & $<3 \%$ & 0 \\
\hline \multirow{4}{*}{ Estradas } & $3 \% \mathrm{a} 8 \%$ & 1 \\
\cline { 2 - 3 } & $8 \% \mathrm{a} 20 \%$ & 1 \\
\cline { 2 - 3 } & $>45 \%$ & 0 \\
\cline { 2 - 3 } & $\leq 50 \mathrm{~m}$ & 0 \\
\hline \multirow{3}{*}{ Hidrografia } & $(50,100] \mathrm{m}$ & 1 \\
\hline \multirow{2}{*}{ Área Urbana } & $(100,500] \mathrm{m}$ & 1 \\
\cline { 2 - 3 } & $(500,1000] \mathrm{m}$ & 0 \\
\cline { 2 - 3 } & $>1000 \mathrm{~m}$ & 1 \\
\cline { 2 - 3 } & $\leq 200 \mathrm{~m}$ & 0 \\
\cline { 2 - 3 } & $>200 \mathrm{~m}$ & 1 \\
\cline { 2 - 3 } & $\leq 2000 \mathrm{~m}$ & 1 \\
\hline
\end{tabular}


Os critérios mais importantes para esta análise foram a distância de manchas urbanas (área urbana), estradas e hidrografia, sendo atribuído o valor binário 1 para critérios favoráveis e valor 0 para critérios restritos ou inaptos.

Segundo Oliveira Neto (2011), a preocupação com a distância entre a fonte geradora de resíduos sólidos urbanos e a área onde será implantado o aterro sanitário merece grande destaque, pois pode inviabilizar o empreendimento. Distâncias longas podem gerar gastos excessivos com combustível e aumentar o tempo entre as coletas. Distâncias curtas podem causar prejuízos e danos à população que mora adjacente ao aterro devido condições de insalubridade e depreciação do valor de imóveis.

As áreas situadas com distância inferior a $50 \mathrm{~m}$ e superior a $1.000 \mathrm{~m}$ foram consideradas áreas inaptas. As áreas situadas entre $100 \mathrm{~m}$ e $1.000 \mathrm{~m}$ foram classificadas como favoráveis.

Quanto à distância de hidrografias, considerando Santos e Girardi (2007), qualquer indústria potencialmente poluidora deve ficar localizada a uma distância mínima de $200 \mathrm{~m}$ dos recursos hídricos ou cursos d'água mais próximos. Sendo assim, áreas localizadas a uma distância inferior a $200 \mathrm{~m}$ foi classificada como inapta, recebendo o valor binário 0 . Áreas localizadas a distância superior a $200 \mathrm{~m}$ foi classificada como favorável e recebendo o valor binário 1 .

Os valores binários atribuídos para pedologia e declividade foram definidos considerando o grau de fragilidade do terreno, sendo o valor 1 para terrenos com baixa fragilidade, valor 0 para terremos com média e alta fragilidade. 0 valor 0 foi atribuído a fatores restritivos, ou seja, para fatores que impossibilitariam a implantação de um aterro sanitário, sendo eles: distância de vias inferiores a $50 \mathrm{~m}$ ou superiores a $1.000 \mathrm{~m}$, distância de cursos d'água inferior a $200 \mathrm{~m}$ e distância de áreas urbanas inferiores a $2.000 \mathrm{~m}$.

A Figura 5 demonstra o fluxograma lógico seguindo os objetivos propostos para a obtenção da análise final e detalha melhor a distribuição dos critérios na classificação proposta.

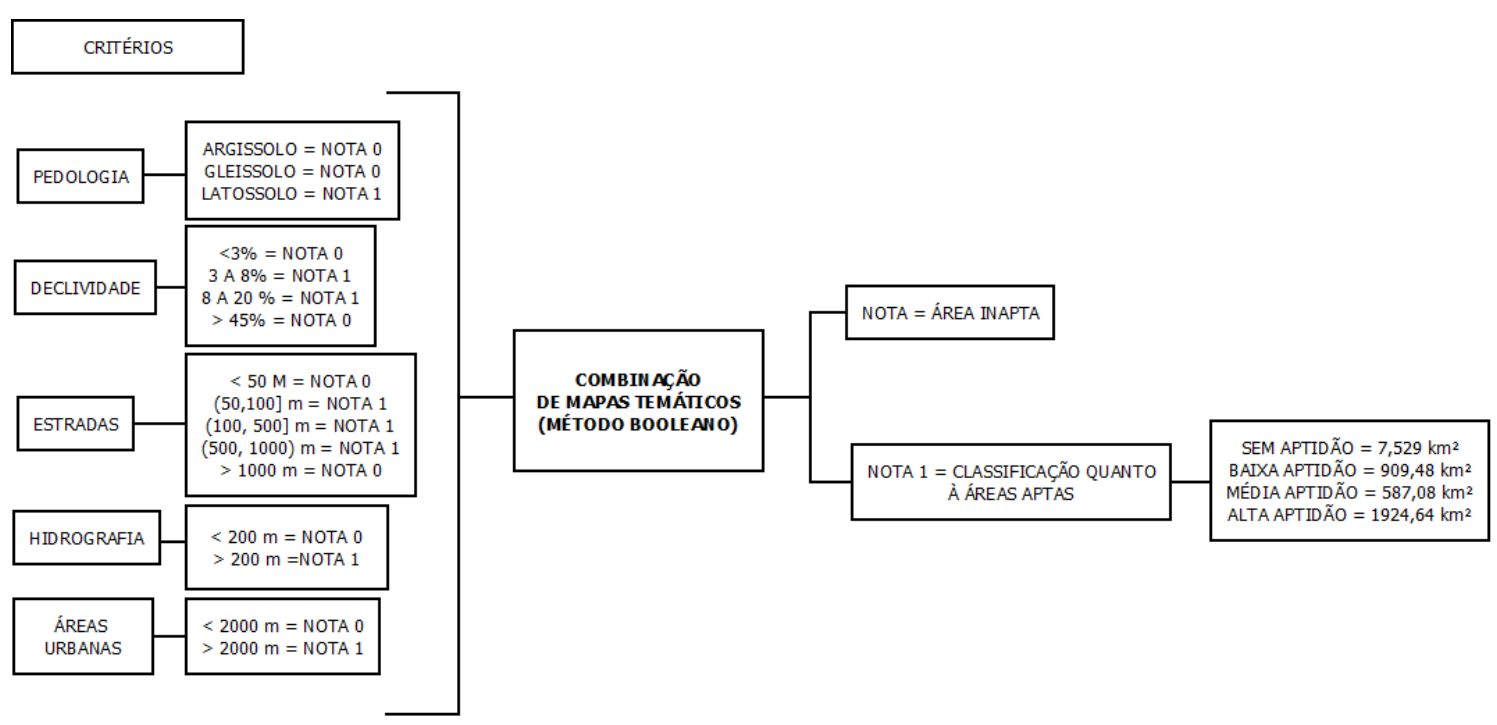

Figura 5. Fluxograma lógico. 
Padronizados os critérios de aptidão e restrição com seus respectivos valores booleanos, utilizou-se a ferramenta Calculadora Raster do software QGIS, que possibilita a aplicação da lógica booleana, gerando o mapa de aptidão para instalação do aterro sanitário (Figura 6).

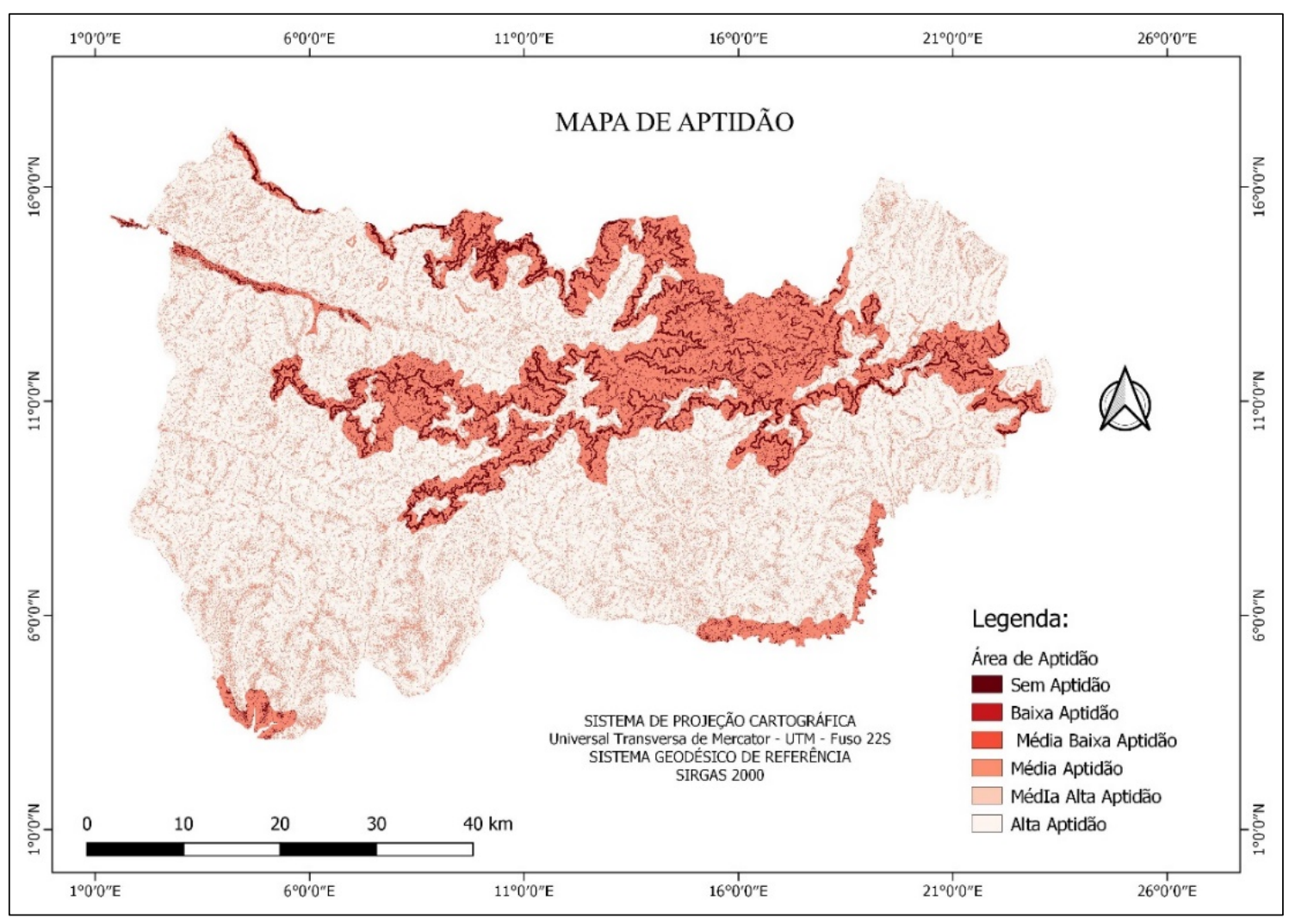

Figura 6. Mapa de aptidão para instalação de aterro sanitário no Município de Campina Verde (MG).

Analisando o mapa de aptidão para a instalação de aterros sanitários, nota-se que as áreas aptas se localizam em regiões de baixa fragilidade do solo, ou seja, em regiões de Latossolo e com baixa declividade. Os Latossolos são solos profundos e com boa estrutura, sendo assim, regiões com baixo índice de fragilidade.

As áreas de menor aptidão se concentram especificamente em regiões de maior fragilidade do solo, sendo regiões de Argissolo que são solos suscetíveis a erosão e regiões de Gleissolos, que são solos hidromórficos apresentando limitações devido à presença de lençol freático e elevado risco de inundações e alagamentos frequentes (Oliveira Neto, 2011). Foi possível verificar que tais áreas apresentaram uma distância elevada das estradas e manchas urbanas se tornando áreas economicamente inviáveis.

As áreas aptas à instalação de aterro sanitário, obtidas através da avaliação por lógica booleana são, portanto, apresentadas na Tabela 2 . 
Tabela 2. Áreas aptas à instalação de aterro sanitário no Município de Campina Verde (MG).

\begin{tabular}{|l|c|c|}
\hline Aptidão & Área Total $\mathbf{( k m}^{\mathbf{2}} \mathbf{)}$ & Área Total (\%) \\
\hline Sem Aptidão & 7,52 & 0,20 \\
\hline Baixa & 909,48 & 25,00 \\
\hline Média & 587,08 & 16,00 \\
\hline Média Alta & 222,02 & 6,10 \\
\hline Alta & $1.924,64$ & 52,70 \\
\hline Total & $3.650,74$ & 100,00 \\
\hline
\end{tabular}

A área de estudo apresenta aproximadamente 53\% do seu território, 1.924,64 km², com características de alta aptidão para instalação de aterro sanitário. As áreas com média aptidão correspondem a $22,10 \%$ da área, ou ainda $809,10 \mathrm{~km}^{2}$. A área de baixa aptidão representa $25 \%$ do território, $909,48 \mathrm{~km}^{2}$. Já as áreas que apresentam restrições absolutas, correspondem a uma porção de $0,20 \%$ do território, $7,529 \mathrm{~km}^{2}$, não sendo assim indicadas para a instalação de aterros sanitários.

\section{Discussão}

Os aterros sanitários são importantes pois solucionam parte dos problemas causados pelo excesso de lixo gerado nas grandes cidades. E ainda, vale ressaltar sobre a forma ambientalmente correta para tratar a disposição de resíduos.

Segundo Born (2013), a avaliação de áreas para a localização de empreendimentos constitui-se em um importante instrumento de planejamento ambiental, pois até mesmo um aterro sanitário que cumpra todos os critérios técnicos de engenharia, se instalado em uma área desfavorável pode vir a causar danos significativos ao meio ambiente e à população.

Portanto, intervir eficazmente através de um processo de auxílio à escolha de áreas para implantação de um aterro sanitário não significa apenas utilizar dados corretos, mas, sobretudo, obter um modelo de raciocínio capaz de traduzi-los em informações capazes de subsidiar as decisões envolvidas neste processo (Born, 2013).

Segundo Lino (2007), o contato com métodos de seleção de áreas para implantação de aterros sanitários permite afirmar que não há um método padrão, adequado a todas as realidades. Segundo Brollo (2004), os parâmetros de análise são inerentes às áreas estudadas e só é possível estabelecer regras rígidas para classes de parâmetros quando há legislação específica.

Com o geoprocessamento de imagens é possível localizar áreas favoráveis à implantação de aterro sanitário, sendo uma maneira rápida e de baixo custo. 0 único pré-requisito é a disponibilidade de imagens de satélite e de dados sobre a região (Santos e Girardi, 2007).

Para Miranda et al. (2019), o uso da lógica booleana permite que as análises espaciais sejam facilitadas com a aplicação da ferramenta, possibilitando uma investigação rápida, porém eficaz, e uma melhor visualização do município como um todo. E ainda, os autores destacam que o fato de se trabalhar com critérios que possuem uma delimitação espacial e a sua integração, elimina de maneira eficiente a subjetividade na escolha dos locais para a implantação, ponto esse que poderia gerar conflitos entre gestão e comunidade local, bem como direciona para uma maior sustentabilidade ambiental deste tipo de empreendimento.

Diante disto, por meio da modelagem booleana foi possível determinar as áreas adequadas para implantação de um aterro sanitário considerando critérios ambientais e baseando-se na legislação vigente. Dessa maneira, o método se mostrou eficiente, uma vez 
que o resultado foi satisfatório, pois considerando fatores ambientais relevantes as áreas aptas para a implementação do aterro foram apontadas de forma clara.

\section{Conclusão}

Através deste estudo foi possível confirmar que as ferramentas de geoprocessamento podem ser utilizadas nas tomadas de decisões com fins de planejamento ambiental, agregando objetividade e clareza ao resultado.

O desenvolvimento deste trabalho, de acordo com a metodologia proposta, possibilitou o alcance dos objetivos estabelecidos, mesmo com a limitação de dados disponíveis para a Região de Campina Verde (MG). Contudo, é importante frisar que o estudo foi realizado de forma remota, sendo assim, necessárias visitas às áreas aptas para identificação do uso do solo na região. Contudo, é imprescindível que haja mais estudos e um maior investimento do poder público para que se possa cumprir a meta da Política Nacional de Resíduos Sólidos (Brasil, 2010) de eliminar os lixões no Brasil. Uma saída viável seria investir em soluções regionais, onde um conjunto de municípios faria um consórcio intermunicipal para tratamento de seus resíduos.

Por fim, o SIG Quantum GIS mostrou-se uma ferramenta prática e confiável para a seleção de áreas mais adequadas à instalação de aterro sanitário. Sendo uma ferramenta livre e eficaz, que visa a minimizar os impactos ambientais causados pelo empreendimento.

\section{Agradecimentos}

Os autores agradecem à Agência de Infraestrutura Estadual de Dados Espaciais de Minas Gerais (IEDE), ao Instituto Prístino, ao Portal de Geologia de Minas Gerais e à EMBRAPA pelo fornecimento das bases de dados usadas nessa pesquisa, e a toda comunidade QGis Brasil pelo suporte prestado.

\section{Conflito de interesses}

Os autores declaram não haver conflito de interesses.

\section{Referências}

ABNT - Associação Brasileira de Normas Técnicas. ABNT NBR 8419: Apresentação de projetos de aterros sanitários de resíduos sólidos urbanos - Procedimento. Rio de Janeiro: ABNT, 1992.

ABNT - Associação Brasileira de Normas Técnicas. ABNT NBR 13896: Aterros de resíduos não perigosos - Critérios para projeto, implantação e operação. Rio de Janeiro: ABNT, 1997.

ABRELPE - Associação Brasileira de Empresas de Limpeza Pública e Resíduos Especiais. Panorama dos Resíduos Sólidos no Brasil. São Paulo: ABRELPE, 2012.

Amaral, D. G. P. Uso de geoprocessamento para indicação de áreas favoráveis à construção de aterro sanitário no Município de Ouro Preto (MG). Caderno de Geografia, v. 27, n. 51, p. 642-655, 2017. https://doi.org/10.5752/p.2318-2962.2017v27n51p642

Batty, M.; Almeida, C. M.; Câmara, G.; Monteiro, A. M. V. (Orgs.). Geoinformação em urbanismo: cidade real X cidade virtual. São Paulo: Oficina de Textos, 2007. 
Besen, G. R. Lixo. In: Ricardo, B.; Campanili, M. (Orgs.). Almanaque Brasil socioambiental. São Paulo: Socioambiental, 2007.

BNDES - Banco Nacional de Desenvolvimento Econômico e Social. Análise das diversas tecnologias de tratamento e disposição final de resíduos sólidos urbanos no Brasil, Europa, Estados Unidos e Japão. 2. ed. Jaboatão dos Guararapes: BNDES, UFPE, 2014.

Born, V. Avaliação da aptidão de áreas para instalação de aterro sanitário com uso de ferramentas de apoio à tomada de decisão por múltiplos critérios. Lajeado: Centro Universitário Univates, 2013. (TCC de Graduação).

Boyler, C. B. História da Matemática. Nova Iorque, Dover, 1968.

Brasil. Lei no 12.305, de 2 de agosto de 2010. Institui a Política Nacional de Resíduos Sólidos; altera a Lei no 9.605, de 12 de fevereiro de 1998; e dá outras providências. Disponível em: <http://www.planalto.gov.br/ccivil_03/_ato2007-2010/2010/lei/ 112305.htm>. Acesso em: 24 abr. 2020.

Brollo, M. J. Seleção de áreas para implantação de aterros sanitários. Anais do RESID’2004 - Seminário sobre Resíduos Sólidos, São Paulo, ABGE, 2004.

Câmara, G.; Moreira, F. R.; Barbosa, C.; Almeida Filho, R.; Bönisch, S. Técnicas de inferência geográfica. In: Câmara, G.; Davis, C.; Monteiro, A. M. V. Introdução à Ciência da Geoinformação. São Paulo: INPE, 2017.

Colavite, A. P.; Passos, M. M. Integração de mapas de declividade e modelos digitais tridimensionais do relevo na análise da paisagem. Revista Geonorte, v. 2, n. 4, p. 15471559, 2012.

FEAM - Fundação Estadual do Meio Ambiente. Panorama da destinação dos resíduos sólidos urbanos no Estado de Minas Gerais em 2018. Belo Horizonte: FEAM, 2019.

Figueredo Neto, A. G.; Silva, C. N. A.; Costa, G. J. A.; Sousa, J. G.; Assis, H. J. S. Uso de geotecnologias para designação de áreas propícias à construção de aterro sanitário no Município de Teresina-PI. Anais do 1o Congresso Sul-Americano de Resíduos Sólidos e Sustentabilidade, Gramado, 2018. Disponível em: <https://www.ibeas.org.br/conresol/ conresol2018/XI-016.pdf>. Acesso em: 23 jan. 2020.

Franco, J. B. S.; Rosa, R. Zoneamento agrícola do Município de Campina Verde-MG, utilizando técnicas de sensoriamento remoto e sistema de informação geográfica. Anais do IX Simpósio Brasileiro de Sensoriamento Remoto, Santos, p. 561-572, 1998.

Hamada, J. Concepção de aterros sanitários: análise crítica e contribuições para seu aprimoramento no Brasil. Bauru: UNESP/FEB, 2003. (Tese de Livre Docência).

IBGE - Instituto Brasileiro de Geografia e Estatística. Censo demográfico 2010. Rio de Janeiro: IBGE, 2017.

IBGE - Instituto Brasileiro de Geografia e Estatística. Agência IBGE - Notícias 2019. Rio de Janeiro: IBGE, 2019.

Jucá, J. F. T. Destinação final dos resíduos sólidos no Brasil: situação atual e perspectivas. Anais do X Simpósio Luso-Brasileiro de Engenharia Sanitária e Ambiental, Braga, 2002.

Lino, I. C. Seleção de áreas para implantação de aterros sanitários: análise comparativa de métodos. Rio Claro: Universidade Estadual Paulista, 2007. (Dissertação de mestrado).

Miranda, G. L.; Simião, J. B.; Abreu, P. H. S.; Vieira, E. M. Minimização do conflito na gestão do território por meio do emprego da lógica booleana e critérios geoambientais para 
definição de áreas favoráveis à implantação de aterro sanitário: estudo de caso no Município de Itabira-MG. Holos Environment, v. 19, n. 4, p. 578-595, 2019. https://doi.org/10.14295/holos.v19i4.12353

Oliveira Neto, J. T. Determinação de áreas favoráveis à implantação de aterro sanitário de resíduos sólidos urbanos para o Município de Piumhi-MG. Belo Horizonte: Universidade Federal de Minas Gerais, 2011. (Monografia de especialização).

Oliveira Neto, M. B. Gleissolo. AGEITEC - Agência Embrapa de Informação Tecnológica. 2011. Disponível em: <http://www.agencia.cnptia.embrapa.br/gestor/territorio_ mata_sul_pernambucana/arvore/CONT000gt7eon7k02wx7ha087apz2kfhpkns.html>.

Acesso em: 28 maio 2020.

Portella, M. O.; Ribeiro, J. C. J. Aterros sanitários: aspectos gerais e destino final dos resíduos. Revista Direito Ambiental e Sociedade, v. 4, n. 1, p. 115-134, 2014.

Samizava, T. M.; Kaida, R. H.; Imai, N. N.; Nunes, J. O. R. SIG aplicado à escolha de áreas potenciais para instalação de aterros sanitários no Município de Presidente Prudente-SP. Revista Brasileira de Cartografia, v. 60, n. 1, p. 43-55, 2008.

Santos, J. S.; Girardi, A. G. Utilização de geoprocessamento para localização de áreas para aterro sanitário no Município de Alegre. Anais do XIII Simpósio Brasileiro de Sensoriamento Remoto, INPE, Florianópolis, 2007.

Silva, A. D. Geotecnologias e as problemáticas dos resíduos sólidos urbanos em Tefé, AM. Manaus: Universidade Federal do Amazonas, 2009. (Dissertação de mestrado).

Informação da Licença: Este é um artigo Open Access distribuído sob os termos da Licença Creative Commons Attribution, que permite uso irrestrito, distribuição e reprodução em qualquer meio, desde que a obra original seja devidamente citada. 